\title{
Inclusive Multicultural Videos: An Engaging Approach in Teaching Higher Educational Levels of English
}

\author{
Bassmah B. AITaher \\ School of Basic Sciences and Humanities, German Jordanian University, Jordan
}

Received June 15, 2020; Revised July 27, 2020; Accepted August 25, 2020

\begin{abstract}
Cite This Paper in the following Citation Styles
(a): [1] AlTaher, Bassmah B. "Inclusive Multicultural Videos: An Engaging Approach in Teaching Higher Educational Levels of English," Universal Journal of Educational Research, Vol. 8, No. 10, pp. 4536-4544, 2020. DOI: 10.13189/ujer.2020.081022.
\end{abstract}

(b): Bassmah B. AlTaher (2020). Inclusive Multicultural Videos: An Engaging Approach in Teaching Higher Educational Levels of English. Universal Journal of Educational Research, 8(10), 4536-4544. DOI: 10.13189/ujer.2020.081022.

Copyright $\bigcirc 2020$ by authors, all rights reserved. Authors agree that this article remains permanently open access under the terms of the Creative Commons Attribution License 4.0 International License

\begin{abstract}
Students studying different levels of English require special attention in a higher educational classroom, especially when such levels are part of a university requirement and are not treated with the same focus as specialty courses. Hence, the aim of this study is to implement a teaching method that uses multicultural videos throughout an English level course to enhance student learning. This paper uses a survey approach given to students of different majors registered in two English levels at the German Jordanian University. In total, 53 students have responded. Ordinal scales are used through descriptive statistics analysis with a frequency check of the demographic data. Cronbach's alpha is calculated for each section of the survey, proving a valid consistency of three dependent variables. DV1 $\alpha=0.935$, DV2 $\alpha=0.930$, and DV3 $\alpha=0.921$. A one-way ANOVA test was then used in order to interpret the relationship between the independent variable: multicultural videos, and the three dependent variables. The results of this study confirm the hypothesis that there is a positive relationship between multicultural videos and their dependent variables, reflecting on how this particular method promotes inclusive teaching in a higher educational classroom, and can help students from different cultural and educational backgrounds participate and engage fruitfully. Through this study, the Universal Design for Learning is tested on higher educational students without disabilities but have debility of different educational and cultural backgrounds, making the need for a material source, such as multicultural videos, used to promote inclusive education, which is an important factor when teaching English as a foreign language.
\end{abstract}

Keywords Inclusive Teaching, Multicultural Videos, English as a Foreign Language, Higher Education

\section{Introduction}

In the midst of learning new vocabulary in a higher educational classroom of 25 to 30 students, an English teacher highlights new words in a text by asking, "What do you think the word illuminate means?" The teacher looks around the room for answers and sees some students on their mobile phones; some are searching a dictionary app, while others stare at the teacher dumbfounded. When two to three students raise their hands and answer, the teacher changes their method in order to encourage students to participate and include them in further discussions. This simple situation is reflected throughout the levels of English taught in higher educational institutions in Jordan, particularly at the German Jordanian University.

With the accessibility of higher education, the number of students enrolled at universities has amplified globally in recent years (Macfarlane, \& Burg, 2017). The same thing is happening in Jordan; many students register by the thousands in public and private universities every year. Therefore, the large numbers of students taking a mandatory course, such as English as a foreign language require a lot of preparation from the teacher, especially when they are taught in advanced levels. An intermediate English course at the German Jordanian University (GJU), for example, has a regular classroom of 30 registered 
students, sometimes reaching 35 students per section. This may seem low compared to other public university students in Jordan that have 100 to 150 students per lecture, yet GJU demands quality rather quantity. A mandatory course, such as English 101 is filled with students from different high school experiences, different cultural backgrounds, and of different levels of English. With this wide variety of students, getting them motivated during the lecture becomes a challenge, especially when the course being taught has low credit hours, and students tend to not take it seriously.

Every instructor at any university has the desire to promote openness among their students, in addition to helping them explore change and allow students to speak their minds (Gillett-Swan and Sargeant, 2015). It is in the individuality each student presents in class that makes it challenging for teachers to put together a Universal Design for Learning (UDL). An instructor changes their idealist methodologies after seeing the difference in students' abilities. The situation becomes more challenging when undergraduate students tend to focus on their specialty courses rather than on their obligatory university courses that seem too easy and irrelevant. At GJU, many university requirements are placed in their study plan with a total of 21 compulsory credit hours and 6 elective courses. Six levels of English are an obligatory course for the university's seven schools that offer various majors.

Students go through a placement test when they first enter enroll at the university, and based on their results, they are placed in their right level. Levels 5 and 6 are mandatory for students who have achieved high scores in the test. Due to the university's international status as being part of the German and the Jordanian government's project in infusing the best of both worlds, students have to reach a good level of English and German before going to Germany for their final academic year.

The English Division at the School of Basic Sciences and Humanities follows the Common European Framework of Reference for languages (CEFR) on a six-point scale. The department issues a beginner, intermediate, and advanced certificate, being C2 as the highest score a student can achieve. The importance of having a good English and German proficiency is important for students seeking internship in Germany when they go for their final year. Since GJU is a public university, special scholarships are presented to Jordanian students, like the student military scholarship for the sons and daughters of the Jordanian army ("Military Scholarships", 2019).

Since students who study at the university are of different nationalities and backgrounds, the barrier that separates students is not only due to ethnic, cultural, and economic differences, but also due to academic differences (Fisher, 1997). Students who studied the national high school program (Tawjihi) have weaker English skills than those who have studied the international high school program, such as the International Baccalaureate (IB), International General Certificate of Secondary Education (IGCSE), or the Scholastic Aptitude Test (SAT). The national program has its challenges, particularly when it comes to English. Many Jordanian students study at public schools, where proper instructions are inapplicable in the classroom because many teachers tend to neglect interactive teaching (Alhabahba et al., 2016), and prefer the traditional method of teaching instead. Private schools, on the other hand, have a slight advantage over public schools as a result of the different programs students are exposed to. Yet, some of these schools face a problem in the quality of its teaching (Al-Tawil and Al-Manseer, 2011).

Despite the challenges schools in Jordan face, students who enroll in international programs tend to have better English skills than those in the national program, because their subjects are taught in English and demand English as their L1 to sit for their high school exams. This opposes the national program where many of its students are weak in the English language, since the majority of their subjects, beside English, are taught in Arabic, students do not really need to have a high command of English to obtain their high school degree.

As a result, when these students enroll in their undergraduate programs at various universities, the discrepancy among most of the students from both programs is clear. This can be seen at GJU, where many students registered in English are seen to display different stages of their proficiency in the language. Those who come from an international program are quite fluent and achieve high grades, while those who have studied the national program vary from low to intermediate in their performance. The challenge lies in the institutions' ability to create inclusivity when having this large amount of diversity amongst its students.

This paper will focus on the English level course and its flexible content at GJU to explore inclusivity when using multicultural videos, as a resource material, aid student interaction and learning abilities in class. The current curriculum for the English course focuses on diversity to encourage student performance, but achieving inclusivity amongst students in EFL has not yet been explored. Aside to the mandatory midterm and final exams, there are two in-class writing tasks, an oral presentation, like an academic conversation, debate, or persuasive speech, depending on the level of the students registered ("English Department Curriculum", 2019). The book chosen to be taught for the fall and spring semesters of 2019 - 2020 is National Geographic's Life (2018), and with an array of interesting reading comprehensions and engaging conversations. Each unit ends with a video that completes the theme of the unit (Hughes, 2018 and Dummett, 2018).

The English course is vital for students to progress in their academic affairs, as it is tied to many of their academic activities, from traveling to Germany to finding 
internships. This is why inclusive education is important in the classroom, especially in a flexible course such as English. It encourages students to speak their minds and build proper respectful conversations in formal settings. Moreover, when they receive the English certificate, it helps them to proceed further in their education and profession. This competitive situation to obtain a $\mathrm{C} 1$ or $\mathrm{C} 2$ when graduating English level six becomes important for senior students, and also becomes an opportunity for the teacher to use various resources that aid inclusive education, especially when an obvious discrepancy is found amongst the students' English level when asked to answer certain questions in English or perform a speech in class. Students who find it difficult to maintain a good pace with the essential material find themselves lost (Thomas \& Muñoz, 2016), and so resort to their mobile phone apps in order to translate English words into Arabic, or simply hide away by scrolling irrelevant pages and avoid participation. Some of those who are competent find the material easy, but do not participate because they presume that they know it all, and resort to their mobile phones to amuse themselves. It truly is a challenge for the instructor, and inclusive teaching is the key in maintaining a healthy environment that allows students to engage in class.

\section{Literature Review}

According to the Universal Design for Learning (UDL) created by the Center for Applied Special Technologies, there are three instructional methods teachers should follow (Orr \& Hammig, 2009). The first method is the way the materials are presented to students. Some materials can be introduced through "visuals, manipulatives, and technology to make the materials more readily understood and accessible" (Orr \& Hammig, 2009, p.182). Secondly, an effective method to keep students engaged is their response to the material presented, whether it is through writing, composing, conversing etc. The final method is based on how students are able to engage throughout the learning process as they find out what interests them and motivates them. For example, playing video games, listening to popular music, and watching videos are some examples that fascinate students and keep them focused. UDL aims at helping students learn while embracing their differences, ensuring that students receive equal opportunities in an education that "best suits their individual needs" (Orr \& Hammig, 2009, p.182).

The main factors required to achieve different methods of learning through UDL are representation, expression, and engagement. How students engage with the material presented throughout their lesson is important, but to create a lesson plan that suits everyone turns into a challenge. Hence, UDL is an important tool for teachers when creating their curriculum, for it enables students to learn and access information, as long as it does not burden students with unnecessary methods that only create barriers. The key to an effective education is to create a global content that motivates a healthy "proactive" environment (Orr \& Hamming, 2009).

It is important to create an effective form of communication when teaching at any level, because teachers are the sole communicators who can bond with a student effectively, and the concept of learning depends on more than one person. However, can inclusive education be effective to students without disabilities? According to a study conducted by Tsang (2013), the results show students without disabilities have also benefited from an inclusive education, because many students did not know how to communicate with one another properly and needed guidance and care. UDL thus becomes beneficial because it allows teachers to be flexible while integrating technology throughout their lessons.

In a course filled with students that come from different backgrounds, this study aims to achieve an inclusive educational experience by using UDL when conducted in a higher educational course, and attempting to discover if multicultural videos are effective. Their inadequate circumstantial background hinders their opportunity to learn. Communicating successfully in class does not always come easy, as each student's understanding of the instructions given differ from one person to another (Barnlund, 1970). Physical instructions are clearer when given in physical indications (Powell and Dana, 2004).

Interactive multimedia is an important form of development program that offers teachers the freedom to choose from different types of graphics, audio, video and so on to focus on a particular topic (Fisher, 1997). By doing so, an ineffective classroom becomes an effective and interactive one in a UDL curriculum. With the availability of diverse content that tackle almost every theme, teachers today are able to be creative and include the participation of all the students in class, especially with the advancement of technology and the spread of smart phones and social media. Students of today are able to understand different ideas and theories from various sources (Koong and $\mathrm{Wu}$, 2011).

When students watch something interesting online, listen to a funny story, or play an interactive game, teachers encourage the "playful approach" (Whiteboard, 2006) that helps students obtain new information by transforming a serious atmosphere into a fun, lively and collaborative environment. Moreover, using animation in teaching has become popular, because it raises "conceptual understanding by promoting the formation of dynamic mental models of phenomena" (M. and Tyagi, 2018, p.1203). This is why short, meaningful videos during class can invoke positive outcomes. Understanding this proper tool aids teaching methods and encourages inclusiveness. Hence, the teacher must set a clear goal to help in the transparency of the outcome (Rose \& Meyer, 2002). It is vital that "social interactions and culture are central to 
learning” (Souto-Manning \& Martell, 2016, p.22). A teacher must learn to be flexible, and not expect too much from a student who is incapable of performing properly in class.

Henceforward, using the most interactive tool in a classroom is useful, as it supports the argument of this study by helping students from different educational and cultural backgrounds learn something new, especially in a higher educational English course.

\section{Research Theory}

Every student is different, unique, and special, especially students with a disability. Such students have their own way of motivation, and their responsiveness in class are sometimes different from those of their peers (Capp, 2017). Hence, UDL has universal and special instructions prepared that would help each student bloom in a class environment. Interacting with students at a high level of communication is essential to learning. In future, inclusive education becomes an essential factor in schools to encourage disabled children to enter a normal learning classroom and help them adapt in a normal environment in order to feel equal to their peers (Zagona, 2017). Inclusive education cannot only be used for the disabled, but also to students who are different in the sense of educational, ethnic, and religious backgrounds (Kozleski, 2016).

Inclusive education is also vital for higher education, for it urges a sense of belonging and companionship, and these are the aspects that should have proper strategies when conducting them in class (Soodak, 2003). Positivity is key in creating a collaborative environment, and diversity among students is essential. An ideal inclusive class is to embrace each student's different response and to treat the classroom as one social community, where all students have the opportunity to get involved in the learning process (Nilholm \& Alm, 2010). It is important that a teacher's attitude upholds inclusive values or else the process would not work (Kurawa, 2010), respecting that each student, disability or not, is special and he or she can succeed (Ashman, 2012).

To apply inclusivity in a lecture, it is significant to apply a "pedagogical approach" (Kurawa, 2010) that encourages the use of all kinds of material and resources in class that promotes participation and learning. A strong curriculum and an organized environment help maintain inclusive education. When a challenging situation arises, it is best to address the situation with positivity and proactivity, and this in return becomes an important aspect in inclusive teaching, promoting the "positive behavioral support" (Soodak, 2003).

When teaching English at GJU, it is important to have all students break the language barrier they face nowadays. In order to achieve that, multicultural videos are used as a resource material for this purpose, and explore how they aid student learning in class. The National Geographic videos presented in the material chosen have rich content and engaging exercises that strike interesting conversations, for many of them focus on different cultures and exciting lifestyles, and activities. The videos prove to be relevant a source material that generates student class engagement and cooperation, as the instructor encourages students to converse in English in pairs or in groups. This specific situation is what is being explored.

\section{Research Methodology}

\section{Scope and Sampling}

The sample population $(\mathrm{N}=53)$ is taken from four sections, three sections are of level 6, and one section is of level 4. As shown in figure 1, the independent variable (IV) is related to inclusive teaching using multicultural videos to encourage interactivity of students and the learning of English. To see if there is a positive outcome, the IV is tested to see if it has a relationship to three dependent variables (DVs). The first DV is related to the pronunciation of words and recognizing their spelling in class. The second DV tests whether the videos have helped students learn new words, and the third DV observes if the videos promote interaction in the classroom.

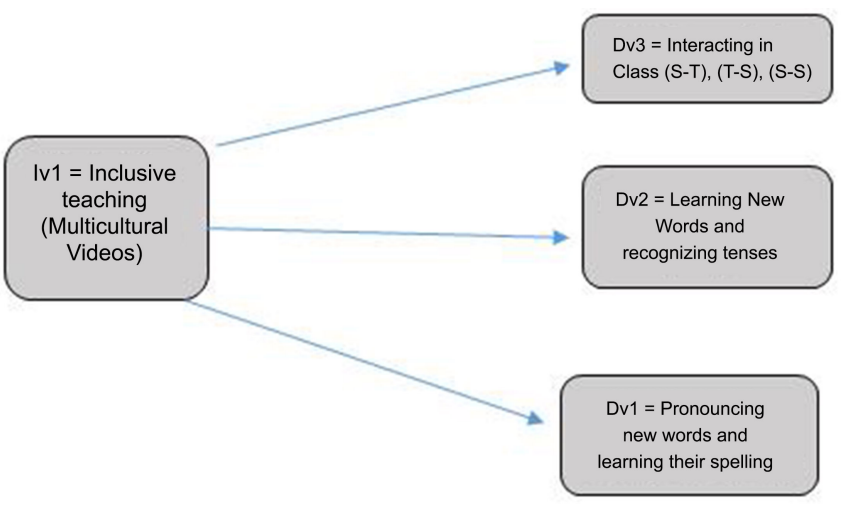

Figure 1. Relationship between the IV and DVs

\section{Research Setting}

At the end of each unit of every level, a video is presented according to the theme of the unit. The videos usually range between 5 to 7 minutes, and students are given questions related to the video in order to answer in pairs or groups. A conversation is ensued as many of the students comment on the events and characters they have seen. The lecture ends with a set of new vocabulary given in the form of a guessing game as part of the video's activities, so students find out the meaning of certain words, idioms, and expressions. After finishing all the required videos in six lectures in duration of fourteen weeks, students were asked to complete a survey based on their experience in class when watching the videos. Students 
registered in English levels four and six vary from freshmen to senior students from different majors, like engineering, business, humanities, logistics, and pharmaceutical.

\section{Data Collection and Methods of Statistical Analysis}

Through a survey-based approach, the questions are divided into three sections. The first section collected demographic data in order to see the students' level, their kind of high school education, method of paying tuition fees, and residency, because all of these factors explain the discrepancy many students have. The results of the demographic details are used in a nominal scale, having calculated their frequency in order to further understand the reason of miscommunication amongst students, while the second part of the survey containing dichotomous questions, inferential statistics are analyzed through ANOVA in order to see if there is a positive relationship between the variables.

\section{Findings and Discussion}

When analyzing the demographic details' frequencies, the number of students that have studied in private schools is more than those who have studied in government schools.
The valid percent of students who have studied in a private school/ international program is $18.9 \%$ and in a national program is $54.7 \%$ as opposed to $7.5 \%$ of students who have studied in a public school/ national program. It is important to note that public schools in Jordan do not teach the international program. More importantly, the total valid percent of students who have studied the national program is $62.2 \%$, and that clarifies the discrepancy of the English language that students show in class.

Another important factor is having students on a military scholarship with a valid percent of $15.1 \%$, which means that there are students who need to get a high grade in this level and have to adapt quickly into their new environments as soon as possible. Moreover, students who live in the capital, Amman, are $81.1 \%$ as opposed to those who live in rural areas, like Madaba $11.3 \%$, the Airport Road 5.7\%, and Petra $1.9 \%$. These statistics explain why some students are shy in class because of the conservativeness of the rural areas' societies as opposed to the liberal capital society (AlTaher, 2019).

When asking the students if they have learned something through the videos, $90 \%$ of the students answered (yes), while $10 \%$ said (no). For the second part of the questionnaire, the responses of the students are as follows in Table 1: 
Table 1. Dependent Variables and their Items

\begin{tabular}{|c|c|c|c|c|c|c|c|c|c|c|c|c|}
\hline \multirow{3}{*}{$\begin{array}{c}\text { Dependent Variable } \\
1 \\
\text { Pronouncing new } \\
\text { words and learning } \\
\text { their spelling }\end{array}$} & \multicolumn{2}{|c|}{$\begin{array}{l}\text { Q1.1 Did you notice the } \\
\text { spelling of the new words } \\
\text { in the videos? }\end{array}$} & \multicolumn{2}{|c|}{$\begin{array}{c}\text { Q1.2 Did you like the style of the } \\
\text { conversations? }\end{array}$} & \multicolumn{2}{|c|}{$\begin{array}{l}\text { Q1.3 Did you realize the } \\
\text { differences in the } \\
\text { accents? }\end{array}$} & \multicolumn{2}{|c|}{$\begin{array}{l}\text { Q1.4 Were you able to } \\
\text { follow the pace of the } \\
\text { spoken English? }\end{array}$} & \multicolumn{2}{|c|}{$\begin{array}{l}\text { Q1.5 Were you able to } \\
\text { pronounce new words from } \\
\text { the videos properly? }\end{array}$} & \multicolumn{2}{|c|}{$\begin{array}{l}\text { Q1.6 Did the vocabulary } \\
\text { question at the end help } \\
\text { your pronunciation? }\end{array}$} \\
\hline & Yes & No & Yes & No & Yes & No & Yes & No & Yes & No & Yes & No \\
\hline & $88.6 \%$ & $11.4 \%$ & $88.7^{\circ}$ & $11.3 \%$ & $79.2 \%$ & $20.8 \%$ & $92.5 \%$ & $7.5 \%$ & $81.8 \%$ & $18.9 \%$ & $96.2 \%$ & $3.8 \%$ \\
\hline \multirow{3}{*}{$\begin{array}{l}\text { Dependent Variable } \\
2 \\
\text { Learning new words } \\
\text { and recognizing } \\
\text { grammar }\end{array}$} & \multicolumn{2}{|c|}{$\begin{array}{l}\text { Q2.1 Did the subtitles help } \\
\text { you recognize new words } \\
\text { and expressions? }\end{array}$} & \multicolumn{2}{|c|}{$\begin{array}{c}\text { Q2.2 Did you learn new words } \\
\text { that are based on the theme of the } \\
\text { video? }\end{array}$} & \multicolumn{2}{|c|}{$\begin{array}{l}\text { Q2.3 Have you noticed } \\
\text { the tenses used in the } \\
\text { videos? }\end{array}$} & \multicolumn{2}{|c|}{$\begin{array}{l}\text { Q2.4 Is it easier to apply } \\
\text { the tenses after watching } \\
\text { the videos? }\end{array}$} & \multicolumn{2}{|c|}{$\begin{array}{l}\text { Q2.5 Were the subtitles } \\
\text { helpful in identifying the } \\
\text { tenses? }\end{array}$} & \multicolumn{2}{|c|}{$\begin{array}{l}\text { Q2.6 Did the vocabulary } \\
\text { questions help you focus on } \\
\text { certain expressions and } \\
\text { idioms? }\end{array}$} \\
\hline & Yes & No & Yes & No & Yes & No & Yes & No & Yes & No & Yes & No \\
\hline & $81.1 \%$ & $18.9 \%$ & $83 \%$ & $17 \%$ & $79.2 \%$ & $20.8 \%$ & $84.9 \%$ & $15.1 \%$ & $92.5 \%$ & $7.5 \%$ & $96.2 \%$ & $3.8 \%$ \\
\hline \multirow{3}{*}{$\begin{array}{l}\text { Dependent Variable } \\
3 \\
\text { Interacting in Class } \\
(\mathrm{S}-\mathrm{T}),(\mathrm{T}-\mathrm{S}),(\mathrm{S}-\mathrm{S})\end{array}$} & \multicolumn{2}{|c|}{$\begin{array}{l}\text { Q3.1 While watching the } \\
\text { videos, were you interested } \\
\text { in the culture, people, and } \\
\text { theme? }\end{array}$} & \multicolumn{2}{|c|}{$\begin{array}{l}\text { Q3.2 While watching, did } \\
\text { you ask for your classmate's } \\
\text { help? }\end{array}$} & \multicolumn{2}{|c|}{$\begin{array}{l}\text { Q3.3 Did the videos } \\
\text { motivate you discuss its } \\
\text { theme? }\end{array}$} & \multicolumn{2}{|c|}{$\begin{array}{c}\text { Q3.4 Did you like answering } \\
\text { the questions with your } \\
\text { peers? }\end{array}$} & \multicolumn{2}{|c|}{$\begin{array}{l}\text { Q3.5 Did you discuss the } \\
\text { topics of the videos in } \\
\text { groups? }\end{array}$} & \multicolumn{2}{|c|}{$\begin{array}{l}\text { Q3.6 Were the questions } \\
\text { easier to answer in class? }\end{array}$} \\
\hline & Yes & No & Yes & No & Yes & No & Yes & No & Yes & No & Yes & No \\
\hline & $64.2 \%$ & $35.8 \%$ & $60 \%$ & $39.6 \%$ & $55.7 \%$ & $44.2 \%$ & $88.7 \%$ & $11.4 \%$ & $67.9 \%$ & $32.1 \%$ & $51 \%$ & $49 \%$ \\
\hline
\end{tabular}


To find out the validity of the study, the three variables contained six items in dichotomous questions. The items were measured in an ordinal scale. The response of the students were translated into a nominal scale, and Cronbach's alpha $\alpha$ was calculated. The target answer of this study is (yes) in order to observe if multicultural videos have helped students learn in an inclusive manner. An $\alpha=$ 1.00 shows a perfect internal consistent reliability, and an $\alpha$ $=0.00$ indicates no consistency in measurement (Nunnally, 1978). The Cronbach alpha for DV1 is $\alpha=0.935$, DV2 $\alpha=$ 0.930 , and DV3 $\alpha=0.921$. The results are within the range of a consistent measurement. As for the IV, the videos related to each unit's theme resulted in the following frequency, as unit six was the majority of the student's favorite reaching a $22.6 \%$ vote.

To analyze the observational data such as a survey, ANOVA is the most appropriate form of analysis (Iversen and Norpoth, 1987). A one-way ANOVA model is used to test whether an independent variable has different means on a metric-dependent variable, especially when there are more than one category that is determined by one independent variable. The effects made between the IV and the DVs are interrelated. ANOVA is aimed at understanding the differences between two groups. By doing so, the mean value of the dependent values is observed and how the differences of the mean values are affected by the controlled independent variable (Malhotra and Dash, 2011).

The null hypothesis of the test states that there is no significant relationship between the IV and the DVs. The DVs were calculated to produce a SUM average of the six items found in each DV to create new individual variables in order to ease the one-way ANOVA test. The number of the population remained the same $(\mathrm{N}=53)$. The results of the assumption of homogeneity of variance were tested in SPSS and were found tenable using Levene's Test. The significance values of Levene's test (Sig), the numbers are greater than 0.05 , so the test has not violated the homogeneity of variance. See Table 2.

Table 2. Test of Homogeneity of Variances

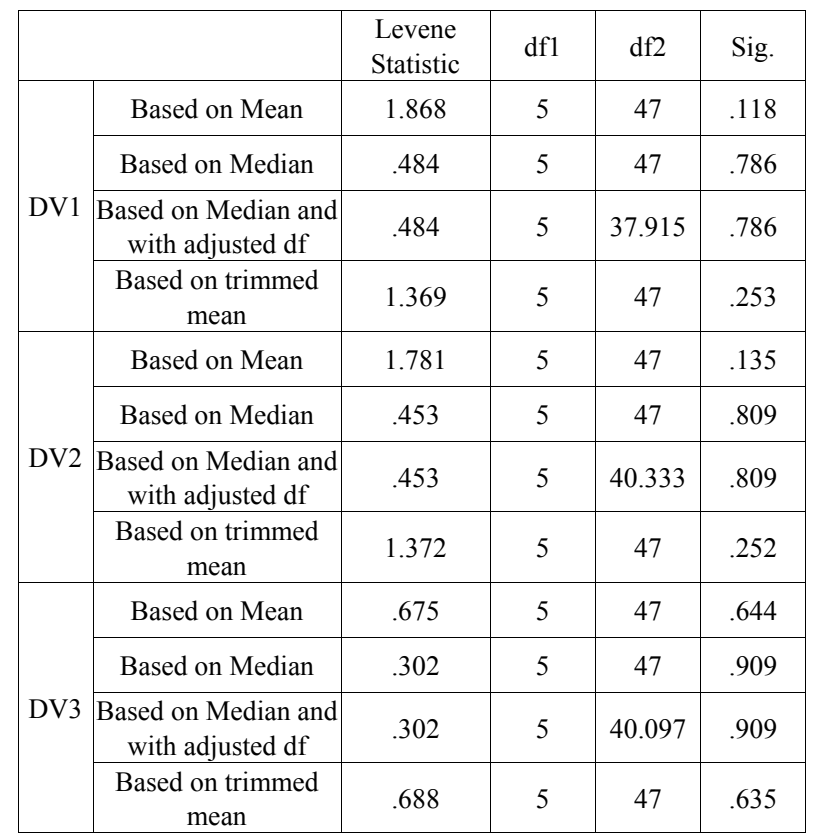

Since the Homogeneity of the assumption was tenable, the ANOVA results in Table 3 were the next step. In the column (Sig.), the significant of value is more than 0.05 , showing that there is no significant difference amongst the means between the three dependent variables. See Table 3.

Thus, there is significant evidence to reject the null hypothesis and conclude that there is a significant relationship between the variables, proving that class interaction, learning new words and their spelling, as well as for recognizing tenses and how they are properly used. The DVs were strongly interconnected with the IV.

Table 3. One-Way ANOVA Test

\begin{tabular}{|c|c|c|c|c|c|c|}
\hline & & Sum of Squares & $\mathrm{df}$ & Mean Square & $\mathrm{F}$ & Sig. \\
\hline \multirow{3}{*}{ DV1 } & Between Groups & .219 & 5 & .044 & .484 & .786 \\
\hline & Within Groups & 4.246 & 47 & .090 & & \\
\hline & Total & 4.464 & 52 & & & \\
\hline \multirow{3}{*}{ DV2 } & Between Groups & .209 & 5 & .042 & .453 & .809 \\
\hline & Within Groups & 4.332 & 47 & .092 & & \\
\hline & Total & 4.541 & 52 & & & \\
\hline \multirow{3}{*}{ DV3 } & Between Groups & .444 & 5 & .089 & .506 & .770 \\
\hline & Within Groups & 8.238 & 47 & .175 & & \\
\hline & Total & 8.681 & 52 & & & \\
\hline
\end{tabular}




\section{Conclusions}

A normal English section at GJU has non-native speakers of English, and by using multicultural videos as part of a UDL curriculum in an English course at a higher educational institution has proven to be an effective method in engaging students to be more proactive in class, thus ensuring an inclusive education. Throughout the videos, the teacher is able to recognize the diversity of the students. The videos have not only helped students learn new words, spelling, and tenses, but have also given them an opportunity to discuss issues such as global affairs and different cultures and lifestyles with their peers. Throughout their discussions, students embrace different opinions and learn how to respect one another while answering specific questions between themselves. The interesting used in the multicultural videos enhances learning opportunities as they pave the way to a proper conversation. Inclusivity ensures a solid partnership amongst students and their teacher, recognizing each simple comment, listening to each idea, and promoting an exciting environment. The videos uphold a form of inclusive education by captivating the attention of the students registered in levels four and six at GJU, making them interact with the material, instructor, and peers. As teachers require all students to achieve high standards, the variation of student abilities is seen as an opportunity for students who are pressured into achieving the very best of grades. Teachers will add to the curriculum further videos as those used in this situation to achieve a better pace and involvement in class.

\section{Research Limitations}

The study is performed at one public university and tested on two English levels, restricting the findings from being able to be generalized properly. Therefore, future research in this area are encouraged, especially when using inclusive materials for all levels of English, and comparing those levels to other courses of language, like the mandatory German level courses taught at GJU.

\section{REFERENCES}

[1] "English Department Curriculum", (2019), School of Basic Sciences and Humanities, German Jordanian University, Retrieved from https://mygju.gju.edu.jo/faces/index.xhtml

[2] "Military Scholarships," Social and Economic Institution for Retired Military and Fighters, 1 July 2019, Retrieved from http://www.esarsv.com/Details.aspx?Lng=\&type $=7 \& \mathrm{id}=15$ 032

[3] Alhabahba, Mohammad Madallh and Pandian, Ambigapathy and Mahfoodh, Omar Hassan Ali. (2016),
"English language education in Jordan: Some recent trends and challenges", Curriculum \& Teaching Studies, Vol.6 March 2016, pp.1-14. http://dx.doi.org/10.1080/2331186X. 2016.1156809

[4] AlTaher, B. (2019), "The necessity of teaching Intercultural Communication in higher education", Journal of Applied Research in Higher Education, Vol. ahead-of-print No. ahead-of-print.

https://doi.org/10.1108/JARHE-04-2019-0082

[5] Al-Tawil, Hani \& Al-Manseer, Lameeha (2011), Developing A Strategy for Controlling Education Problems at Jordanian Private Schools, Dirasat: Educational Sciences, Vol.38 Issue 4, pp.1378-1398.

[6] Ashman, A.F. (2012). Facilitating inclusion through responsive teaching. In K. Topping \& C. Boyle (Ed.), What Works in Inclusion? (pp. 81-97). Maidenhead, Berkshire: McGraw-Hill Education.

[7] Barnlund, D. (1970), "Behavior: book of readings in communication", in Akin et al. (Eds), Language Behavior: A Book of Readings in Communication, De Gruyter Mouton, The Hague, pp. 43-61.

[8] Capp, M. J. (2017). "The effectiveness of universal design for learning: A meta-analysis of literature between 2013-2016". International Journal of Inclusive Education, $21,791-807$.

[9] Dummett, Paul, (2018), "Life - Advanced Student's Book", 2nd ed., National Geographic Learning.

[10] Fisher, Joseph B. \& Deshler, Donald D., (1997), "The Effects of an Interactive Multimedia Program in Teacher's Understanding and Implementation of an Inclusive Practice,' Learning Disability Quarterly, Vol.22 Spring 1999, pp.127-142.

[11] Gillett-Swan JK \& Sargeant J., (2015), "Wellbeing as an accrual process: beyond subjectivity and beyond the moment", Social Indicators Research, 121(1): 135-148. DOI: 10.1007/s11205-014-0634-6.

[12] Iversen, G.R. \& Norpoth, H. (1987), "Analysis of variance", Series: Quantitative Applications in the Social Sciences, 2nd ed., Sage Publications, Newbury Park, CA.

[13] Koong, C.S. \& Wu, C.Y. (2011), "The applicability of interactive item templates in varied knowledge types", Computers \& Education, Vol. 56 No. 3, pp. 781-801.

[14] Kozleski, Elizabeth B., and Yu, Iris (2016), Inclusive Education. obo in Education. doi: 10.1093/obo/9780199756 810-0162

[15] Kurawa, G. (2010). Teaching diversity in a primary school: examining teachers classroom strategies for inclusion. Procedia Social and Behavioral Sciences, 5, 1585-1591. doi:10.1016/j.sbspro.2010.07.329

[16] M., Shreesha, \& Tyagi, Sanjay Kumar, (2018), "Effectiveness of Animation as a Tool for Communication in Primary Education", International Journal of Educational Management, Vol.32 No.7, pp.1202-1214.

[17] Macfarlane, Bruce \& Burg, Damon (2019) Legitimation, professionalisation and accountability in higher education studies: an intergenerational story, Studies in Higher Education, 44:3, 459-469, DOI: 10.1080/03075079.2017.13 
76640

[18] Malhotra, N. \& Dash, S. (2011), Marketing Research - An Applied Orientation, 6th ed., Dorling Kindersley (India), Licensees of Pearson Education in South Asia, New Delhi.

[19] Nilholm, C., \& Alm, B. (2010). An inclusive classroom? A case study of inclusiveness, teacher strategies, and children's experiences. European Journal of Special Needs Education, 25(3), 239-252, DOI: 10.1080/08856257.2010.492933

[20] Nunnally, J.C. (1978), Psychometric Theory, McGraw-Hill, New York, NY.

[21] Orr, Ann C. \& Hammig, Sara Bachman, (2009), "Inclusive Postsecondary Strategies For Teaching Students With Learning Disabilities: A Review Of The Literature," Learning Disability Quarterly, Sage.

[22] Powell, R.G. \& Dana, P. (2004), Classroom Communication and Diversity: Enhancing Instructional Practice, 2nd ed., Routledge, New York, NY.

[23] Rose, D., \& Meyer, A. (2002). Teaching every student in the digital age: Universal design for learning. Alexandria, VA: Association for Supervision and Curriculum Development. Rose, D., Meyer, A., \& Hitchcock, C. (2005).

[24] Soodak, L. C. (2003). Classroom Management in Inclusive Settings. Theory Into Practice, 42(4), 327-333. DOI:

$$
\text { 10.1207/s15430421tip4204_10 }
$$

[25] Souto-Manning, \& Martell, Jessica, (20160), Reading, Writing, and Talk: Inclusive Teaching Strategies for Diverse Learners, $K-2$, New York: Teachers College Press.

[26] Stephenson, Helen, (2018), "Life - Intermediate Student's Book", 2nd Ed, National Geographic Learning.

[27] Thomas, K., \& Muñoz, M. A. (2016). Hold the Phone! High School Students' Perceptions of Mobile Phone Integration in the Classroom. American Secondary Education, 44(3), 1937.

[28] Tsang, K. L. V. (2013). Secondary pupils' perceptions and experiences toward studying in an inclusive classroom. International Journal of Whole Schooling, 39-60.

[29] Whiteboard, D. (2006), "Creativity, problem-solving and playful uses of technology: games and simulations in the early years", in Hayes, M. and Whitebread, D. (eds), ICT in the Early Years, Open University Press, Maidenhead, pp. 86-106.

[30] Zagona, Alison L., \& Kurth, Jennifer A., (2017), and MacFarland, Stephanie Z. C., "Teachers' Views of Their Preparation for Inclusive Education and Collaboration," Teacher Education and Special Education, Vol. 40(3) 163178 